\title{
18 infectiepreventie
}

(

,

.

\section{DE GROTE NURSING}

\section{In deze coronatijd is weer duidelijk hoe belangrijk infectiepreventie is.}

Hoe staat het met jouw kennis daarover? Test het met deze 30 vragen (en blader

naar pagina 23 voor de antwoorden). Je kunt de quiz ook maken op Nursing.nl.

tekst Ron Legerstee illustraties IStock/Dr Microbe, AdobeStock/Ralwel

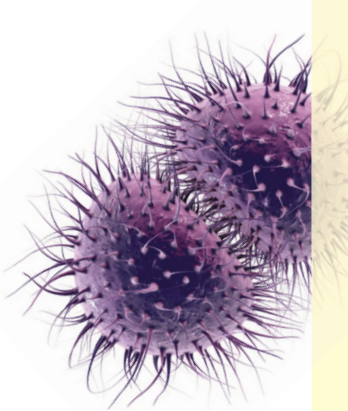

Bij welk type microbe komt de vorm (rond, staafvormig, langwerpig, spiraalvormig etc.) terug in de omschrijving?
a Bacteriën
b Schimmels
c Virussen
d Protozoën

Stoffen aflomstig van gedode gramnegatieve micro-organismen kunnen leiden tot verergering van zielkteverschijnselen. Welke stoffen zijn dat?
a Virusdeeltjes
b Exotoxines
c Flagellen
d Endotoxines

Hoe heet de slijmlaag die bacteriën vormen, waardoor ze minder gevoelig worden voor effectieve behandeling?
a Glycocalyx
b Biofilm
c Celwand
d Mucosa

Stelling I: De bron van infectie wordt wel reservoir genoemd (bijv. voedsel, water, dieren, materiaal)

Stelling II: Virulentie is de mate waarin een micro-organisme ziekmakend is a I en II zijn juist

b I is juist; II is onjuist

c I is onjuist; II is juist

d I en II zijn onjuist

Welk micro-organisme heeft altijd
levende cellen nodig om zich te
vermenigvuldigen?

a Bacterie

b Schimmel

c Protozo

d Virus

6 Micro-organismen kunnen het lichaam binnenkomen via:

a de intacte huid

b een porte d'entrée

c intact slijmvlies

\section{Stelling I: Een postoperatieve wondinfectie (POWI) kan leiden tot een verlenging van de opnameduur, verhoging van kosten, en risico op verdere complicaties}

Stelling II: Bij een diepe POWI kunnen verschijnselen aan de oppervlakte ontbreken
a I en II zijn juist
b I is juist, II is onjuist
c I is onjuist, II is juist
d I en II zijn onjuist 


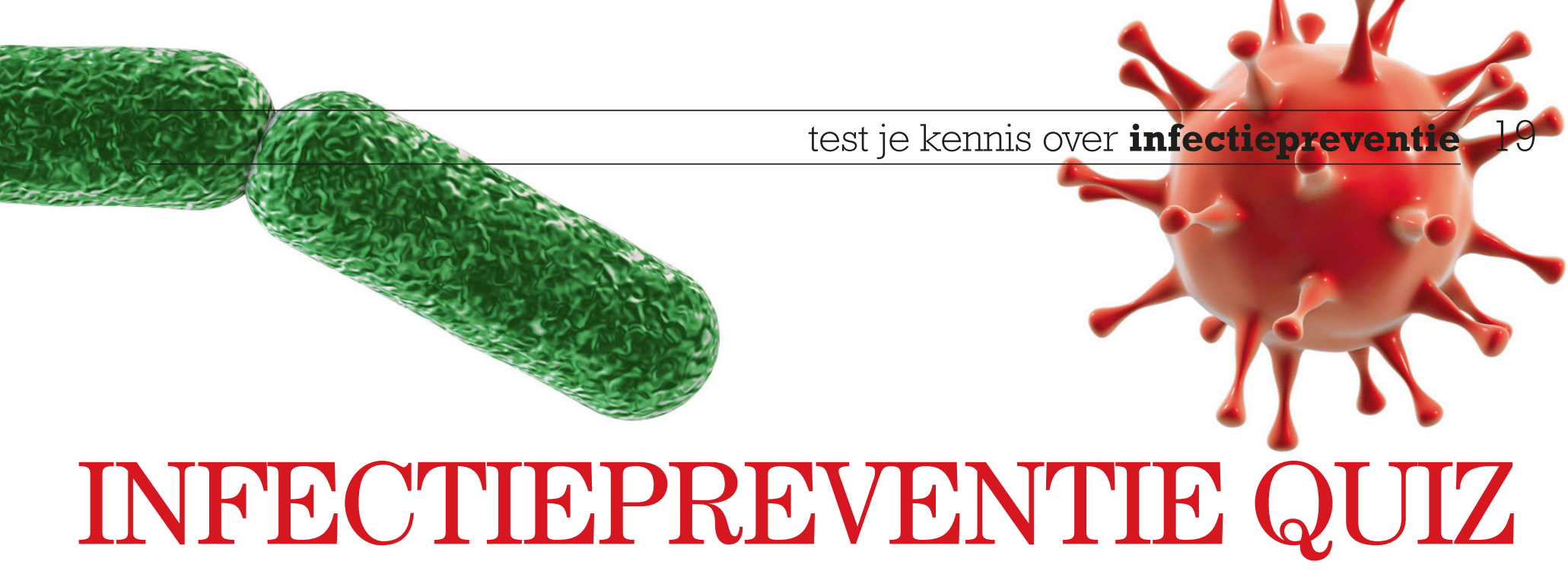

In een 'FFP2-masker' voor gebruik bij patiënten met infecties waarbij aerosolen kunnen vrijkomen (zoals tbc en covid-19) staat de afkorting FFP2 voor ............. Het masker houdt ........... van de partikels tegen.
a Fluid Filtering Face Piece:
$80 \%$
b Filtering Face Piece:
$94 \%$
c Face Filtering Protection:
$99 \%$

Personen die een belangrijke rol hebben gespeeld in de ontwikkeling van infectiepreventie zijn Ignaz Semmelweis (1818-1865), Joseph Lister (1827-1912) en Louis Pasteur (1822-1895). Wat zijn respectievelijk hun bijdragen of inzichten?

a Antisepsis bij operaties; infectiepreventie door handhygiëne; conserveren van voeding

b Conservering van voeding; antisepsis bij operaties; infectiepreventie door handhygiëne

c Infectiepreventie door handhygiëne; antisepsis bij operaties; conserveren van voeding

1 In welke situatie moet je volgens de algemene voorzorgsmaatregelen handschoenen dragen?

a $\mathrm{Bij}$ het hanteren van gebruikt, niet-gedesinfecteerd instrumentarium

b Als er kans is op overdracht van microben via je handen

c Bij mogelijk contact met lichaamsvochten, slijmvliezen en/of niet-intacte huid

$\mathrm{d}$ In alle genoemde gevallen

1 Bacteriën die behoren tot de darmmicrobiota van de mens kunnen bij toiletgebruik door de lucht worden verspreid. Deze verspreiding vindt plaats via...

a grote druppels bij overvloedige diarree b vorming van aerosolen bij het doortrekken

c verontreinigd toiletpapier

$\mathrm{d}$ het gebruik van de luchtverfrisser

12 We zoeken de naam van een 14 verzameling bacteriën van een of meerdere soorten die samen een geleiachtig materiaal produceren om daarbinnen actief te zijn. Oolk zijn ze minder gevoelig voor de invloed van antiseptica en antibiotica. We hebben het hier over een ...

a kolonievormende eenheid (kve)

b slijmzwam

c biofilm

d wondinfectie

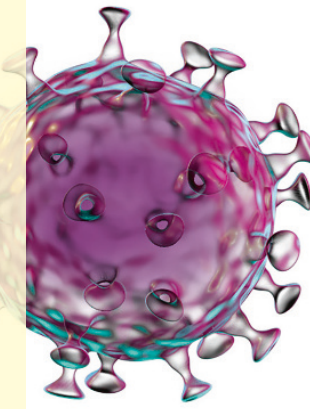

$13 i j$ aanwezigheid van een vreemd lichaam (katheter, infuus et cetera) is weefsel ....... keer gevoeliger voor het ontstaan van een infectie.
a 5
b 50
c 500
d 5000

14 Tegen welk organisme kan de patiënt toepassing van handhygiëne?
a Norovirus
b Clostridium difficile
c MRSA
d Alle genoemde organismen

15

Hoeveel tijd moet je besteden aan het wassen van je handen met water en zeep?

a 10 tot 15 seconden

b 15 tot 30 seconden 


\section{MAAK DEZE QUIZ ONLINE EN WIN}

Als abonnee kun je De Grote Nursing Infectiepreventie Quiz online maken. $\mathrm{Na}$ iedere vraag zie je meteen het juiste antwoord met uitleg: leuk en leerzaam! Maar dat niet alleen; je kunt ook mooie prijzen winnen. Onder de online deelnemers verloten we een Bloomon-boeket, Bol.com-bon, Rituals Pakket en een Pathé Thuis-bon. Ga dus naar Nursing.nl en zoek op Grote Infectiepreventie Quiz of scan de QR-code op pagina 23.

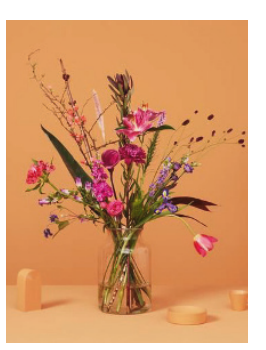

c 40 tot 60 seconden

d 60 tot 90 seconden naar ernstig langs de stappen contaminatie $>$ kolonisatie $>$ lokale infectie $>$ uitbreidende infectie > systemische infectie. In dat laatste stadium kan de patiënt sepsis ontwilkkelen. Wat zijn daarvan de typische symptomen?

a Tachypneu, hypotensie, tachycardie, hypothermie en verwardheid

b Bradypneu, hypotensie, bradycardie, hypothermie en verwardheid

c Bradypneu, hypertensie, bradycardie, hyperthermie en verwardheid

d Tachypneu, hypotensie, tachycardie, hyperthermie en verwardheid

19 Infusietherapie bij de cliënt thuis vereist regelmatige inspectie van de insteekopening. De meest voorkomende veroorzakers van lijninfectie en -sepsis zijn Staphylococcus aureus, Klebsiella pneumoniae, Pseudomonas aeruginosa en Candida-soorten. Bij welke verschijnselen moet je de katheter verwijderen en op een andere plaats opnieuw inbrengen?

a Temperatuurverhoging, pijn bij bewegingen, verwardheid

b Verharding van weefsel rondom de katheter, roodheid, pijn, purulente (etterige) afscheiding

c Ook zonder verschijnselen dient de katheter geregeld te worden vervangen

\footnotetext{
17

a vaccinatie

b antilichamen

$c$ antigeen

$\mathrm{d}$ een booster
} Na het doormaken van covid-19 wordt de weerstand tegen hernieuwd contact met het coronavirus tot stand gebracht door:

Het zogenaamde 'wondinfectiecontinuum' verloopt van minder ernstig

\section{E-LEARNING HYGIËNE EN INFECTIEPREVENTIE}

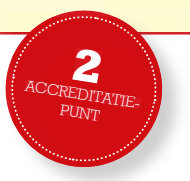

Heb je behoefte aan meer kennis over hygiëne en infectiepreventie, volg dan de e-learning van uitgeverij Bohn Stafleu Van Loghum (eveneens de uitgever van Nursing). Op basis van informatie en uitlegfilmpjes maak je 3 oefentoetsen en 1 eindtoets, waar je 2 accreditatiepunten voor krijgt. De e-learning kost $€ 11,95$ en is aan te schaffen in de BSL Shop: www.bsl.nl/ shop > zoek op 'e-learning hygiëne en infectiepreventie'. 


\section{GRATIS MICROLEARNING HANDHYGIËNE}

(2) Bij het verplegen van een patiënt met covid-19 wordt strikte aerogene isolatie toegepast. Wellke combinatie van persoonlijke beschermingsmiddelen is daarbij essentieel?

a Spatscherm of -bril, steriele handschoenen, mondneusmasker

b Mondneusmasker, isolatiejas lange mouw, handschoenen, veiligheidsbril

c Handschoenen, isolatiejas met lange mouwen en manchet, hoofdbedekking

\section{Welke verpleeglkundige interventie(s) is/zijn specifiek gericht op het} voorkomen van infectieoverdracht van patiënt naar patiënt?

a Geïsoleerd verplegen van een geïnfecteerde patiënt

b Desinfectie van de handen vóór ieder contact met de geïnfecteerde patiënt

c Het vermijden van het gebruik van scherpe hulpmiddelen (naalden, mesjes)

d Alle antwoorden zijn juist

\section{Wat is de juiste volgorde van de 4 verschijnselen van ontstelking?}

a Warmte, pijn, roodheid, zwelling

b Zwelling, pijn, warmte, roodheid

c Roodheid, warmte, zwelling, pijn

d Pijn, warmte, zwelling, roodheid

\section{Zet de 5 momenten van handhygiëne in de juiste volgorde:}

a $\mathrm{Na}$ risico op blootstelling aan lichaamsvloeistof

b Voor schone/aseptische procedure

c Voor het aanraken van de cliënt

d $\mathrm{Na}$ het aanraken van de cliëntomgeving

e $\mathrm{Na}$ aanraken van de cliënt

\section{Om een steriel werkveld te creëren neem je onderstaande stappen (zet op} volgorde):

a Je controleert de verpakking van steriele materialen op openingen, beschadigingen, steriliteitsdatum en -duur.

b Je verzamelt alle benodigdheden, zorgt voor voldoende werkruimte en een afvalemmer met afvalzak binnen handbereik.

In deze microlearning fris je in 5 minuten je kennis op over handhygiëne, handalcohol, hoe je je handen goed kunt verzorgen en de 5 momenten van handhygiëne. Meld je hier aan: www.bsl.nl/microlearnings.

c Je trekt steriele handschoenen aan volgens de geldende procedure.

d Je deponeert de steriele materialen op het werkveld.

e Je creëert een steriel werkveld door een steriele doek of de binnenkant van een steriele verpakking te gebruiken.

f Je verricht een steriele verpleegkundige handeling. $\mathrm{g}$ Je richt je werkveld in op volgorde van handelen.

h Je ruimt op, trekt de handschoenen uit en sluit de afvalzak.

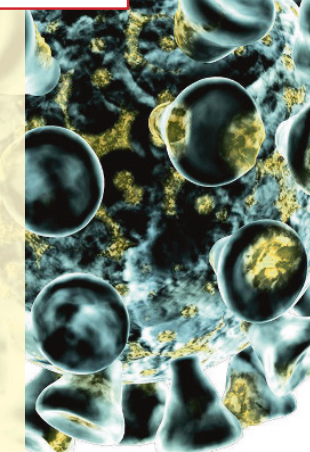

\section{Zet onderstaande stappen van de infectiecyclus in de juiste volgorde}

a Besmettingswegen

b Gastheer met verminderde weerstand

c Besmettingsbron

d Ingangen

e Pathogeen micro-organisme

f Uitgangen

\section{2) Tot de micro-organismen worden} gerelkend.....

(Meerdere antwoorden mogelijk)

$\begin{array}{ll}\text { a teken } & \text { e bacteriën } \\ \text { b virussen } & \mathrm{f} \text { protozoën } \\ \text { c schimmels } & \text { g enzymen } \\ \text { d luizen } & \mathrm{h} \text { gisten }\end{array}$

\section{(2) Handhygiëne houdt in....} (Meerdere antwoorden mogelijlk)
a handen wassen met water en zeep
b handen desinfecteren met handalcohol
c handen verzorgen met vochtinbrengende crème
$\mathrm{d}$ handschoenen dragen

30 Je gebruikt handalcohol als je.... (Meerdere antwoorden mogelijk)

a een cliënt met het norovirus verzorgt

$\mathrm{b}$ een wondverband hebt verwisseld

c een cliënt hebt geholpen bij de toiletgang

$\mathrm{d}$ handen zichtbaar vies zijn 
CLL van loghum

CCS bohn

Stafleu

van loghum

Cohn

stafleu

van loghum

bohn

stafleu

van loghum

- bohn

van loghum

CSS bohn

3 stufleu

van loghum
$\$$ stafleu

8S stafleu

van loghum

CCohn bohn

stafleu

van loghum

$\iint$ bohn $^{2}$

\& stafleu

van loghum

8 stafleu

van loghum

SCS bohn

stafleu

van loghum

SSS bohn

stafleu

CCS bohn

8tafleu

L van loghum

¿S bohn

CCS bohn stafleu

cCohn bohn stafleu

- van loghum

cCeohn

35 stafleu

IL van loghum

cCe bohn

$8)$ stafleu

LL van loghum

cCe bohn

$9)$ stafleu

- van loghum

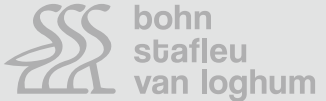

cCe bohn

S) stafleu

van loghum

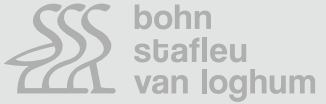

ced bohn

D) stafleu

van loghum

$\int S \begin{aligned} & \text { bohn } \\ & \text { stafleu }\end{aligned}$

C. van loghum

cC bohn

9) stafleu

van loghum

SS bohn

C. van loghum

bohn

stafleu

van loghum
cCe bohn

8 stuafleu

van loghum
SCS bohn

\section{CSS bohn stafleu \\ 1.L van loghum}

van loghum

van loghum

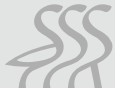

$\sum \int$

CSe bohn

Stafleu

(1) van loghum

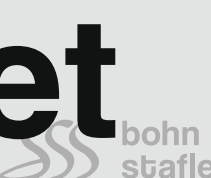

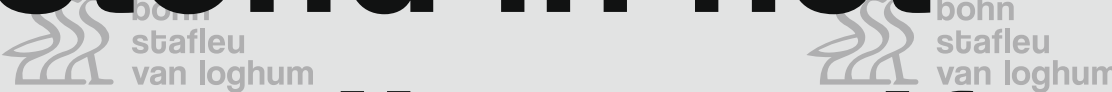

$\int S$

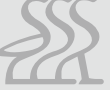

$\int S$

cef bohn

stafleu

$20 \begin{aligned} & \text { bohn } \\ & \text { stafleu } \\ & \text { van loghum }\end{aligned}$
$8 C 2$

4 (1)

stafleu
vag loghum

SC

cec bohn

3 strafleu

van loghum

cC bohn

8 L van loghum

Lan loghum

cec bohn

3 stafleu

cC bohn

8tufleu

C. van loghum

SSS bohn

van loghum

ece bohn

8 stafleu

CL van loghum

CSC bohn

8 stafleu

van loghum

$\operatorname{ses}$

SSS bohn

van loghum

CSS bohn

8) stafleu

CL van loghum

$\int S \begin{aligned} & \text { bohn } \\ & \text { stafleu }\end{aligned}$

van loghum

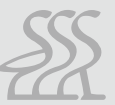

$\int S \begin{aligned} & \text { bohn } \\ & \text { stafleu } \\ & \text { van loghum }\end{aligned}$

CSS bohn

y stafleu

CL van loghum $\iint S \begin{aligned} & \text { bohn } \\ & \text { stafleu }\end{aligned}$ van loghum 


\section{ANTWOORDEN GROTE NURSING INFECTIEPREVENTIE QUIZ}

$\begin{array}{ll}1 & \text { a } \\ 2 & \text { d } \\ 3 & \text { a } \\ 4 & \text { a } \\ 5 & \text { d } \\ 6 & \text { b } \\ 7 & \text { a } \\ 8 & \text { b }\end{array}$

$\begin{array}{ll}9 & \text { c } \\ 10 & d \\ 11 & \text { b } \\ 12 & \text { c } \\ 13 & \text { c } \\ 14 & d \\ 15 & \text { c } \\ 16 & d\end{array}$

17 b

18 d

19 b

20 a

21 b

22 b

23 a

24 c
$25 \mathrm{c}, \mathrm{b}, \mathrm{a}, \mathrm{e}, \mathrm{d}$

26 b, a, e, d, c, g, f, h

27 e, c, f, a, d, b

28 b, c, e, f, h

29 a, b, c

$30 \mathrm{~b}$

\section{TOELTCHTING}

Hieronder lichten we enkele antwoorden toe. De toelichting op alle antwoorden vind je in de online versie van deze quiz (Nursing.nl/magazine of QR-code bovenaan). NVKVV-leden kunnen de toelichting opvragen via administratie@nvkvv.be.

1 a. Bacteriën zijn in te delen naar hun vorm. Bacteriën met een ronde (coccoïde) vorm hebben de eigenschap om zich in clusters of groepen op te houden. We onderscheiden kokken die paarsgewijs liggen (diplokokken); in een vierkant (sarcinae); in de vorm van een druiventros (stafylokokken) of een streep (streptokokken). Deze vormen of groeperingen komen vaak in de Latijnse namen van organismen terug. Ook andere bacteriën hebben vaak een karakteristieke vorm (bijv. spiraal, kurkentrekker, komma) waarmee een - voorlopige - determinatie kan worden gemaakt.

Bron: Hillis DM, Heller HC, Hacker SD, et al. Life - the science of biology. 2020. Sinauer Associates. Sunderland MA.

9 c. Semmelweis, Lister en Pasteur hebben veel betekend voor de infectiepreventie. Zo is Semme/weis bekend van zijn werk rond kraamvrouwenkoorts. De sterfte in 'zijn' kliniek in Wenen was veel groter dan in een andere kliniek, waar vroedvrouwen de bevallingen begeleidden. $\mathrm{Na}$ lang peinzen - en na het overlijden van een bevriend patholoog aan dezelfde verschijnselen als de kraamvrouwen (!) - ontdekte hij dat de infecties via de handen van artsen werden overgebracht. Door implementatie van handhygiëne nam het aantal sterfgevallen sterk af. Lister voerde als chirurg in 1865 de eerste ingreep uit onder een spray van carboloplossing in het operatiegebied. De patiënt, een 11-jarige jongen met verbrijzeld onderbeen, overleefde, net als vele patiënten daarna. Een nieuw tijdperk van antisepsis brak aan.

Pasteur kwam op het idee om vloeistoffen (melk, bier) te verhitten en dan snel af te koelen. Het op deze manier doden van micro-organismen maakte voedingsmiddelen langer houdbaar: pasteuriseren.

\section{Bronnen:}

-Cohen IK. Lessons from the history of wound healing. Clin Dermatol 25, 3-8 (2007).

-Forrest, RD. Development of wound therapy from the Dark Ages to the present. J R Soc Med 75, 268-73 (1982).
12 c. Met het geleiachtig materiaal dat bacteriën kunnen produceren, vormen ze een biofilm die veiligheid biedt aan de microben die erin leven en weerstand tegen middelen die de bacteriën anders zouden kunnen doden (antiseptica) of afremmen in hun groei (antibiotica). Biofilms kunnen zich vormen in wonden, maar ook op katheters, drains, prothesen en dergelijke. Ook bij ziekten waarbij de luchtwegen niet goed functioneren, zoals taaislijmziekte, worden biofilms gevormd. Meer dan 99,99 \% van de op aarde levende bacteriesoorten leeft in een biofilm.

Bron: Hillis DM, Heller HC, Hacker SD, et al. Life - the science of biology. 2020. Sinauer Associates. Sunderland MA.

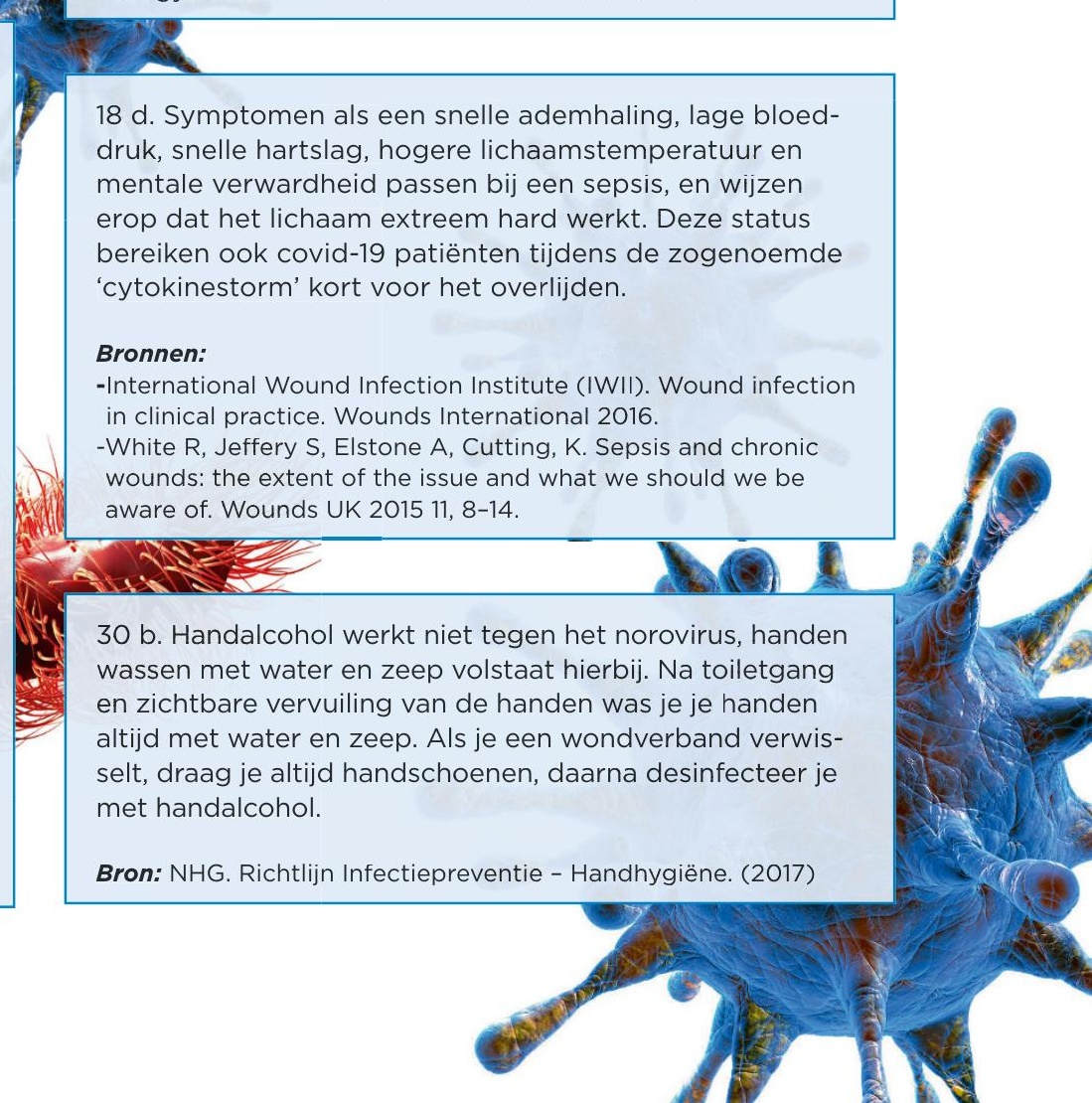

